\title{
Aortic intramural haematoma associated with pulmonary artery periadventitial haematoma
}

\author{
Atsushi Jinno, ${ }^{1}$ Takanobu Hirosawa ${ }^{2}$
}

'Department of Emergency Medicine, Okinawa Yaeyama Hospital, Okinawa, Japan ${ }^{2}$ Department of Diagnostic and Generalist Medicine, Dokkyo Medical University, Tochigi, Japan

Correspondence to Dr Atsushi Jinno, atsushi.jinno@gmail.com

Accepted 27 April 2018

\section{DESCRIPTION}

A 54-year-old man who has a medical history of untreated hypertension presented to the emergency department with sudden onset of back pain and sweat. His back pain suddenly started while he was washing the dishes. The pain was sharp, continuous and radiating to his chest. His vital signs were normal and physical examination revealed neither heart murmur nor pulse deficit. Laboratory test revealed elevated D-dimer level of $2.5 \mu \mathrm{g} / \mathrm{mL}$ (reference range $<0.5 \mu \mathrm{g} / \mathrm{mL}$ ), but normal troponin-T level. Electrocardiography was normal. Chest X-ray showed widened mediastinum.

Non-contrast enhanced and contrast-enhanced CT was obtained. Non-contrast enhanced CT showed crescentic high attenuation sign along the aortic wall from the ascending to the descending aorta (figure 1), whereas contrast-enhanced CT showed a hypoattenuating aortic wall, with no evidence of dissection (figure 2). The haematoma was extended along the aortopulmonary connective sheath (figure 3 ). The patient was transferred to the tertiary hospital and underwent the replacement of ascending aorta. He had an uneventful postoperative course.

Aortic intramural haematoma (IMH) is a subtype of acute aortic syndrome. IMH is distinguished from aortic dissection (AD) in the point of intimal tear exists or not. IMH accounts for $10 \%-25 \%$ of acute aortic syndrome.

CT findings of IMH is crescentic or circular aortic wall hyperattenuation in non-contrast enhanced CT. The CT protocol for the evaluation of acute aortic syndrome should also include non-contrast enhanced CT.

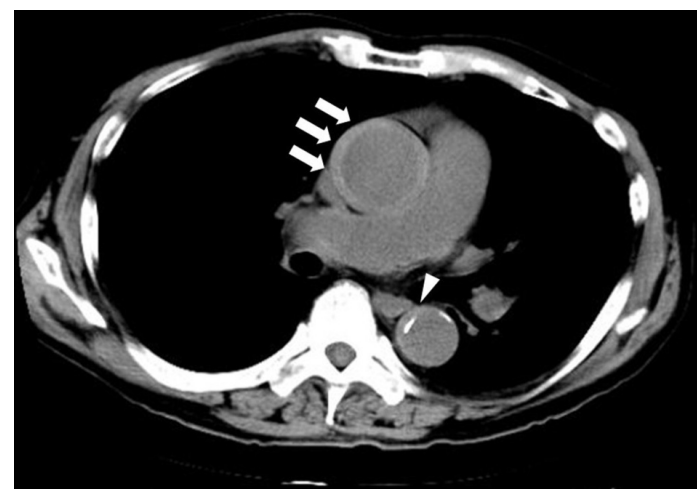

To cite: Jinno A, Hirosawa BMJ Case Rep Published Online First: [please include Day Month Year] doi:10.1136/bcr-2018224853

Figure 1 Axial non-contrast enhanced CT showed circular aortic wall hyperattenuation in ascending aorta (arrows) and displacement of intimal calcifications

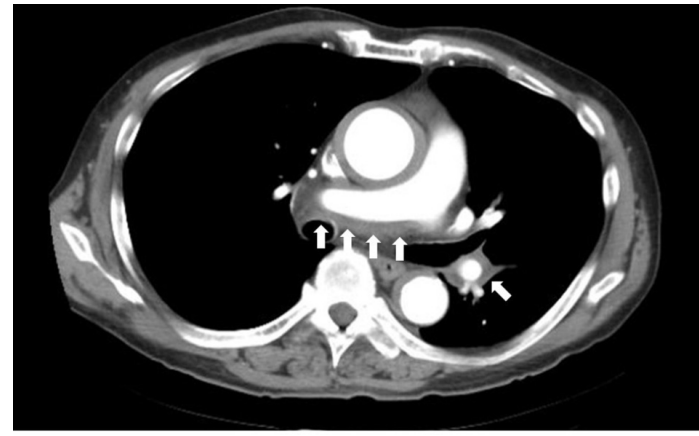

Figure 2 Axial contrast-enhanced CT did not show any intimal tear and contrast agent outpouching, but haematoma around the pulmonary artery was detected (arrows)

Pulmonary artery periadventitial haematoma is a rare complication of IMH. Because ascending aorta and pulmonary trunk have a common adventitia at the root of the great vessels, blood from ruptured $\mathrm{IMH}$ in ascending aorta can extend along the pulmonary artery. Investigators reported the periadventitial haematoma may compress pulmonary artery and restrict the blood flow of pulmonary artery, mimicking pulmonary embolism. ${ }^{2}$

The treatment strategy for IMH is decided based on Stanford Classification and complication such as cardiac tamponade and organ ischaemia. Because patients with type A IMH can develop AD, aortic rupture or aortic aneurysm, the mortality

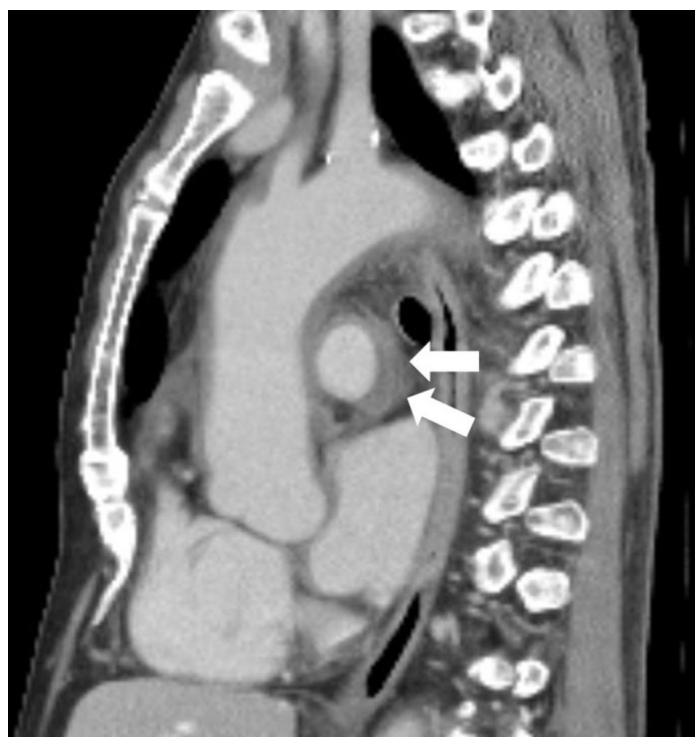
(arrowhead).
Figure 3 Sagittal contrast-enhanced CT scan showed a haematoma extended along the aortopulmonary connective sheath (arrows). 


\section{Patient's perspective}

I was really relieved to know the cause of my back pain.

\section{Learning points}

Contrast-enhanced CT and also non-contrast enhanced CT should be performed for the patients with suspected acute aortic syndrome.

- Pulmonary artery periadventitial haematoma is one of the complications of Stanford type A intramural haematoma (IMH).

- The management of type A IMH is basically surgical intervention.

of patients with type A IMH treated medically is high, about $40 \% .^{3}$ Surgical management, which aims to prevent the progression, clearly reduces the mortality compared with non-operative management, so generally, operative management is indicated for the type A IMH. ${ }^{1}$ The patients who are haemodynamically unstable or have complications such as tamponade or impending rupture need timely surgery. If the patient is stable and has no complications on arrival, some CT features such as maximum aortic diameter $\geq 50 \mathrm{~mm}$ and maximum aortic wall thickness $\geq 11 \mathrm{~mm}$ are reported as predictors of the progression, so timely surgery is recommended in these patients.

Contributors Both authors conceived the study concept and study design. AJ and TH performed complication and synthesis of the data. TH supervised the research project. Both authors participated in interpretation of the results and writing of the report, and approved the final version.

Funding The authors have not declared a specific grant for this research from any funding agency in the public, commercial or not-for-profit sectors.

Competing interests None declared.

Patient consent Obtained.

Provenance and peer review Not commissioned; externally peer reviewed.

(C) BMJ Publishing Group Ltd (unless otherwise stated in the text of the article) 2018. All rights reserved. No commercial use is permitted unless otherwise expressly granted.

\section{REFERENCES}

1 Erbel R, Aboyans V, Boileau C, et al. ESC Guidelines on the diagnosis and treatment of aortic diseases. European Heart Journal 2014;2014:2873-926.

2 Shiau EL, Wu FZ, Huang YL, et al. Aortic intramural hematoma with pulmonary artery extension mimics pulmonary embolism. Am J Emerg Med 2013;31:1538.e3-1538.e4.

3 Harris KM, Braverman AC, Eagle KA, et al. Acute aortic intramural hematoma: an analysis from the International Registry of Acute Aortic Dissection. Circulation 2012;126:S91-S96.

Copyright 2018 BMJ Publishing Group. All rights reserved. For permission to reuse any of this content visit

http://group.bmj.com/group/rights-licensing/permissions.

BMJ Case Report Fellows may re-use this article for personal use and teaching without any further permission.

Become a Fellow of BMJ Case Reports today and you can:

- Submit as many cases as you like

- Enjoy fast sympathetic peer review and rapid publication of accepted articles

- Access all the published articles

Re-use any of the published material for personal use and teaching without further permission

For information on Institutional Fellowships contact consortiasales@bmjgroup.com

Visit casereports.bmj.com for more articles like this and to become a Fellow 